\title{
Gênero, sexualidade e políticas públicas de educação
}

\author{
Gender, sexuality and the public education policies \\ Genero, sexualidade y politicas publicas de educación
}

\author{
DENISE REGINA QUARESMA DA SILVA* \\ ZULEIKA LEONORA SCHMIDT COSTA** \\ MÁRCIA BEATRIZ CERUTTI MÜLLER***
}

\begin{abstract}
$\longrightarrow$
RESUMO

Este estudo de cunho teórico objetiva analisar os documentos legais pertinentes às políticas públicas de educação sobre gênero, sexualidade e educação sexual, estabelecendo reflexões com os cenários educativos. Concluímos que estes fundam pressupostos que são um ponto de partida importante rumo à luta dos movimentos sociais feministas; à luta pelos direitos humanos a respeito dos direitos sexuais e reprodutivos e pelo combate à homofobia; e à luta pela promoção dos direitos humanos e da saúde da população de lésbicas, gays, bissexuais, travestis e transexuais.
\end{abstract}

Palavras-chave: Políticas públicas de educação. Gênero. Sexualidade. Educação sexual.

\begin{abstract}
This theoretical study aims to analyse the legal documents pertinent to the public policies of gender education, sexuality and sex education, establishing reflections with the education scenarios. We concluded that these documents about these matters ground assumptions that are an important starting point towards the struggle of the feminist social movements, the fight for human rights on sexual and reproductive rights, as well as the fight against homophobia, the promotion of human rights and the health of the lesbian, gay, bisexual, transvestite and transgender population.
\end{abstract}

Keywords: Public education policies. Gender. Sexuality. Sex education.

\section{RESUMEN}

Este estudio de cuño teórico, objetiva analizar los documentos legales pertinentes a las políticas públicas de Educación sobre género, sexualidad y educación sexual, estableciendo reflexiones con los escenarios educativos. Concluimos que estos documentos sobre estas temáticas fundan preposiciones que son un punto de partida importante hacia la lucha de los movimientos sociales feministas, la lucha por los derechos humanos sobre los derechos sexuales y reproductivos, también el combate a la homofobia así como la promoción de los derechos humanos y de la salud de la población de lesbianas, gays, bisexuales, travestis y transexuales.

Palabras clave: Políticas públicas de educación. Género. Sexualidad. Educación sexual.

\footnotetext{
* Doutora em Educação, Pesquisadora do PPG em Educação da UNILASALLE/Canoas e do PPG em Diversidade Cultural e Inclusão Social da Universidade Feevale. Pesquisadora CNPq. Pós-doutora em Estudos de Gênero.E-mail: denisequaresmadasilva@gmail.com

*** Doutora em Educação, Unilasalle/Canoas. Professora na Faculdade Cenecista de Osório nos cursos de Psicologia. Coordenadora do curso de Psicologia da Faculdade Cenecista de Osório.E-mail: 1905.psicologia@cnec.br

***Doutora em Educação, Unilasalle/Canoas.E-mail: mceruttimuller@gmail.com
} 


\section{INTRODUÇÃO}

A concepção pretendida neste estudo de cunho teórico sobre gênero, sexualidade e educação sexual nas escolas enfatiza a importância, para além do espaço familiar, que na atualidade esse tema adquiriu. Nesse sentido, a escola pode ser um importante espaço de informação e intervenção sobre as questões de gênero e sexualidade, pois, por muito tempo, este foi (e em muitos casos, continua sendo) um assunto que transitava nos espaços educacionais como um problema moral, um tema "disso não se fala". O objetivo deste estudo é analisar os textos legais pertinentes à temática, estabelecendo reflexões sobre os cenários educativos.

Entende-se que a educação sexual é de uma dimensão mais ampla e percebida como um problema de educação e de saúde pública. A escola, entendida como um espaço de promoção e prevenção em educação de crianças e adolescentes, também deve ser um local privilegiado de implementação dessas propostas educacionais em sexualidade e gênero.

\section{UM PERCURSO CONSTRUÍDO}

Neste estudo, traçamos um percurso histórico sobre a construção de leis e políticas públicas que preconizam as questões envolvendo a diversidade sexual e de gênero. Parte-se da Declaração Universal dos Direitos Humanos (1948), que afirma em seu preâmbulo que o desprezo e o desrespeito pelos direitos humanos resultaram em atos bárbaros que ultrajam a consciência da humanidade. Em seu artigo $2^{\circ}$, declara:

Todos os seres humanos podem invocar os direitos e as liberdades proclamados na presente Declaração, sem distinção alguma, nomeadamente de raça, de cor, de sexo, de língua, de religião, de opinião política ou outra, de origem nacional ou social, de fortuna, de nascimento ou de qualquer outra situação. Além disso, não será feita nenhuma distinção fundada no estatuto político, jurídico ou internacional do país ou do território da naturalidade da pessoa, seja esse país ou território independente, sob tutela, autônomo ou sujeito a alguma limitação de soberania.

Segundo Limongi (1977), essa declaração foi aprovada objetivando assegurar o respeito aos direitos humanos, bem como tratar os casos de violação. Percebe-se, no documento, o papel da educação e da escola nesse processo.

Os anos 1960-1970 foram marcados, no Brasil, de acordo com Dallari (2007), especialmente pela capacidade de resistência do povo diante dos arbítrios e da ausência de respeito às instituições democráticas. Ressaltamos que a educação não se dissocia do respeito, da proteção e da defesa dos seres humanos. Educação justa se faz associando a cultura de direitos com a prática democrática. Naquele mesmo período, as discussões em relação aos direitos sexuais e reprodutivos se davam no campo da saúde reprodutiva, e, em nível internacional, foram promovidas as políticas de planejamento familiar.

$\mathrm{Na}$ sequência, destacam-se alguns dos movimentos mundiais que fomentam as mudanças vindouras: a Declaração Mundial sobre Educação para Todos (1990), que, em seu artigo 3ํ, declara que é necessário universalizar o acesso à educação e promover a equidade, melhorando sua qualidade, bem como tomar medidas efetivas para reduzir as desigualdades; a Declaração de Salamanca; a Conferência Mundial sobre Necessidades Educativas Especiais: Acesso e Qualidade, realizada pela Unesco, em Salamanca (Espanha), em 1994.

Embalada por tais movimentos, desponta, no cenário das políticas públicas em educação no Brasil, a inserção da educação sexual orientada pelo Ministério de Educação e Cultura (MEC) nos Parâmetros Curriculares Nacionais (PCNs), na forma de tema transversal.

Os PCNs têm por objetivo estabelecer uma referência curricular nacional, para construir um parâmetro nacional de conteúdos desde a educação infantil até o ensino médio. No Brasil, essa é a primeira vez que o tema orientação sexual é oficialmente inserido no currículo escolar nacional. De acordo com esse documento, os temas transversais organizam e exploram problemas fundamentais e urgentes da vida social, tais como ética, saúde, meio ambiente, orientação sexual e pluralidade cultural. Porém, a prática docente revela as dificuldades atuais da implementação dessa transversalidade, que é entendida em muitos casos pelos docentes como algo que deva ocorrer se houver alguma situação como uma gravidez precoce. Em uma pesquisa realizada no sul do Brasil, em 2011, nas 56 escolas municipais de ensino fundamental, com 124 docentes, somente 1,8\% dos/as entrevistados/as afirmam que abordam a educação sexual como tema transversal no currículo; $31,8 \%$ declaram que não abordam o assunto, enquanto $12,7 \%$ confirmam que abordam o tema, mas sem vinculá-lo ao currículo. Já $18,2 \%$ falam que abordam o tema, porém se contradizem ao longo do discurso, revelando que não o discutem; e $35,4 \%$ buscam se evadir do tema, quando este é solicitado pelos alunos/as, fazendo emergir outro assunto e trocando o foco da discussão (QUARESMA DA SILVA, 2012).

A partir de meados dos anos 1980, iniciou-se uma demanda por trabalhos na área da sexualidade nas escolas, como um tema e fator constituinte do processo educativo e como uma preocupação dos órgãos públicos. Nessa assertiva, as Secretarias de Educação das esferas municipal e estadual também ocuparam-se em propor projetos de orientação sexual nas escolas. Isto se deu ao 
advento de alguns fatores que preocupavam educadores como as temáticas ligadas ao comportamento sexual de adolescentes, ao crescimento da gravidez das adolescentes e ao aumento da contaminação pelo HIV (vírus da Aids). A princípio, acreditava-se que as famílias apresentavam resistência à abordagem dessas questões no âmbito escolar (RIBEIRO, 2004).

Convém também ressaltar que, em relação a essas questões, nos anos 1970 e 1980, muitas dessas iniciativas em que se abordavam as temáticas relativas à sexualidade acabaram por alimentar uma visão conservadora de educação sexual - uma espécie de política sexual voltada a conter ameaças à família e ataques à normalidade heterossexual (WEEKS, 1999, p. 76). Conforme observa Louro (2004, p. 130), "as políticas curriculares são, então, alvo da atenção de setores conservadores, na tentativa de regular e orientar crianças e jovens dentro dos padrões que consideram moralmente sãos".

As temáticas em torno das sexualidades, homossexualidades, bissexualidades e demais identidades e expressões de gênero não são manifestações novas no espaço escolar, no cenário mundial. No entanto, no Brasil, só a partir da segunda metade dos anos 1980, estas começaram a ser discutidas mais abertamente, no interior de diversos espaços sociais - entre estes, a escola e a universidade (sobretudo nos programas de pós-graduação, a partir dos quais se constituíram núcleos de estudos e pesquisas sobre gênero e sobre a área de Estudos Gays e Lésbicos). Até então, nas escolas, quando os temas relativos à sexualidade apareciam no currículo, ficavam circunscritos às áreas de Ciências ou, eventualmente, à Educação Moral e Cívica, que era uma disciplina adotada pelo Decreto-Lei 869, de 12 de setembro de 1969, que vigorou de 1969 a 1986.

A Constituição Federal de 1988 e o Estatuto da Criança e do Adolescente (ECA) são outros dois documentos fundamentais que embasam uma concepção moderna e democrática sobre os direitos das crianças e dos adolescentes. Em seu artigo 5o, a Constituição define que todos são iguais perante a lei, sem distinções de qualquer natureza, não especificando, no entanto, o tema gênero e sexualidade. O ECA também não chega a afirmar direitos em relação à sexualidade e à saúde sexual e reprodutiva, possuindo antes um caráter de proteção no que diz respeito à exploração da sexualidade pelo mundo adulto (PIROTTA; PIROTTA, 1999).

Essa temática é, então, destacada nas políticas públicas na área de gênero e sexualidade: nos Parâmetros Curriculares Nacionais (1998), propostos pelo MEC, cujo objetivo é incorporar no currículo de forma a compor um repertório articulado e aberto a novos temas, entre estes a orientação sexual; no Programa de Formação de Professores: Gênero e Diversidade na Escola, Orientação Sexual e Relações Étnico-Raciais (2009).
No Brasil, a educação inclusiva está amparada na Lei de Diretrizes e Bases da Educação Nacional (Lei no 9.394/96), que assegura o direito à escola a todas as pessoas (brasileiras ou estrangeiras residentes no país), sem discriminar negativamente singularidades ou características específicas de indivíduos ou grupos humanos. Também, a partir da promulgação da LDB 9394/96, questões referentes à formação de docentes e aos cursos de formação de docentes foram se tornando cada vez mais alvo de discussões.

Em 1997, diversas comissões de especialistas foram instituídas com a tarefa de realizar a elaboração das Diretrizes Curriculares para os cursos de nível superior do país. Entende-se que o tema gênero e sexualidade deve estar presente na formação de professores para atuar na educação básica, tendo o professor a oportunidade de refletir sobre suas crenças, seus valores, seus discursos, suas ideologias, seu posicionamento ante a diversidade cultural, de gênero e sexual. "A universidade tem um papel importante nessa formação, podendo contribuir para uma sociedade menos homofóbica, misoginia e sexista, em prol do respeito e do reconhecimento das diversidades" (CRUZ, 2014, p. 30).

Os temas transversais objetivam incluir as questões sociais no currículo escolar de forma a constituir um repertório articulado e aberto a novos temas. Os Parâmetros Curriculares Nacionais adotam essa tendência e a incluem no currículo, objetivando compor um conjunto articulado e aberto de novos temas, buscando um tratamento didático que contemple sua complexidade e sua dinâmica, dando-lhes a mesma importância das áreas convencionais. $\mathrm{O}$ currículo ganha em flexibilidade e abertura, uma vez que os temas podem ser priorizados e contextualizados de acordo com as diferentes realidades locais e regionais, e outros temas podem ser incluídos (BRASIL - SEF, 1997, v. 8, p. 29).

Ainda em relação aos temas transversais, sua validade apoia-se no sentido que o tema pode trazer à contribuição pedagógica e social:

Por serem questões sociais, os Temas Transversais têm natureza diferente das áreas convencionais. Tratam de processos que estão sendo intensamente vividos pela sociedade, pelas comunidades, pelas famílias, pelos alunos e educadores em seu cotidiano. São debatidos em diferentes espaços sociais, em busca de soluções e de alternativas, confrontando posicionamentos diversos tanto em relação à intervenção no âmbito social mais amplo quanto à atuação pessoal. São questões urgentes que interrogam sobre a vida humana, sobre a realidade que está sendo construída e que demandam transformações macrossociais e também de atitudes pessoais, exigindo, portanto, ensino e aprendizagem de conteúdos relativos a essas duas dimensões (BRASIL, PCNS: TEMAS TRANSVERSAIS, 1998, p. 26). 
A orientação sexual como tema transversal é considerada, aqui neste estudo, como imanente aos processos de aprendizagem e composta por um conjunto de atividades escolares, propostas pelo professor, para atingir determinado objetivo (TRAVERSINI; COSTA, 2006). Longe de manter a neutralidade, caracteriza-se por ser historicamente construída, envolvendo formas de saber, relações de poder e construções discursivas. Estas relacionadas com as diferentes áreas do conhecimento, intencionalmente escolhidas para produzir determinado tipo de conduta do sujeito, seja em relação ao conhecimento a ser adquirido/construído, seja em relação aos comportamentos esperados dele como aluno na escola. Independentemente do tempo, do espaço e das condições de seu desenvolvimento, não é possível vincular a metodologia desenvolvida a uma postura progressista ou conservadora do professor (GORE, 1995). Nesse sentido, aponta-se:

\begin{abstract}
A escola, ao definir o trabalho com Orientação Sexual como uma de suas competências, o incluirá no seu projeto educativo. Isso implica uma definição clara dos princípios que deverão nortear o trabalho de Orientação Sexual e sua clara explicitação para toda a comunidade escolar envolvida no processo educativo dos alunos. Esses princípios determinarão desde a postura diante das questões relacionadas à sexualidade e suas manifestações na escola, até a escolha de conteúdos a serem trabalhados junto aos alunos. A coerência entre os princípios adotados e a prática cotidiana da escola deverá pautar todo o trabalho (BRASIL, MEC/PCNS, 1997, p. 299).
\end{abstract}

Desde a apresentação dos PCNs à comunidade educacional e, mais especificamente dos temas transversais, a orientação sexual é designada à escola e a esta tem sido atribuída a responsabilidade de preencher algumas lacunas deixadas pelas famílias, cabendo aos professores das diversas áreas do conhecimento a tarefa de orientação quanto à sexualidade numa perspectiva transdisciplinar (LIRA; JOFILI, 2011).

Porém, diversos estudos (LIRA; JOFILI, 2011; QUARESMA DA SILVA, 2014) revelam que os professores apresentam uma resistência para assumirem, na prática pedagógica, um trabalho sistemático que envolva os vários aspectos da sexualidade, procurando eximirse dessa tarefa, deixando-a a cargo dos professores de Ciências e/ou Biologia. Os docentes representam a sexualidade como um fator fundamental sobre o qual os alunos necessitam ser esclarecidos, o que vem demonstrar uma preocupação com problemas sociais, tais como gravidez precoce, aborto e Aids. Porém, apesar de mostrarem-se receptivos à discussão da temática da sexualidade, dizem da dificuldade existente em abordá-la, pois encontra-se associada aos valores, aos tabus e aos preconceitos de cada um/a.

Considera-se como ponto de partida de ações no âmbito educacional que abordaram as temáticas sobre sexualidade e gênero no período de 2006 a 2015 o Programa de Combate à Violência e à Discriminação contra GLTB (Gays, Lésbicas, Transgêneros e Bissexuais) e de Promoção da Cidadania de Homossexuais "Brasil sem Homofobia" (BRASIL, 2004). Avaliado este como um programa de base fundamental para ampliação e fortalecimento do exercício da cidadania no Brasil.

É importante ressaltar, como política governamental para as questões de gênero e sexualidade, o Plano Nacional de Políticas para as Mulheres (BRASIL, 2004), através da Secretaria Especial de Políticas para as Mulheres da Presidência da República (SPM/ PR), que foi criada em 1 o de janeiro de 2003, com status de ministério. No seu item 7, esse plano destaca o reconhecimento da violência de gênero, raça e etnia como questão estrutural e histórica, que expressa a opressão das mulheres e que precisa ser tratada como assunto de segurança, justiça e saúde pública; e também ressalta a inclusão das questões de gênero, raça e etnia nos currículos escolares. No item 10 , o documento pontua a busca de práticas educativas, a produção de conhecimento, a educação formal, a cultura e a comunicação não discriminatórias.

A 3a Conferência Nacional de Políticas para as Mulheres (3 $3^{\text {a }}$ CNPM) ocorreu em dezembro de 2011, com 200 mil participantes em todo o país e 2.125 delegadas na etapa nacional. Como resultado, tem-se o PNPM 2013-2015, com ainda maior inserção das temáticas de gênero em diversas frentes do governo. Destacam-se aqui os itens (2) Educação para igualdade e cidadania e (9) Enfrentamento do racismo, sexismo e lesbofobia.

Em 2014, foi aprovado o Plano Nacional de Educação $(\mathrm{PNE})^{1}$, Lei $\mathrm{n}^{\mathrm{O}}$ 13.005, de 25 junho de 2014, com vigência por dez anos. O plano indica: "Construção de uma nova ética [...] de modo a incluir, efetivamente os grupos historicamente excluídos: entre outros, negros, quilombolas, pessoas com deficiências, povos indígenas, trabalhadores do campo, mulheres, lésbicas, gays, bissexuais, travestis e transexuais (LGBT)" (BRASIL, 2011, p. 56).

O documento acima apresentado, PNE (2014), considera dez diretrizes: I - erradicação do analfabetismo; II - universalização do atendimento escolar; III - superação das desigualdades educacionais, com ênfase na promoção da cidadania e na erradicação de todas as formas de discriminação; IV - melhoria da qualidade da educação; $\mathrm{V}$ - formação para o trabalho e para a cidadania, com ênfase nos valores morais e éticos em

\footnotetext{
PNE - Plano Nacional de Educação.
} 
que se fundamenta a sociedade; VI - promoção do princípio da gestão democrática da educação pública; VII - promoção humanística, científica, cultural e tecnológica do país; VIII - estabelecimento de meta de aplicação de recursos públicos em educação como proporção do Produto Interno Bruto (PIB), que assegure atendimento às necessidades de expansão, com padrão de qualidade e equidade; IX - valorização dos/as profissionais da educação; $X$ - promoção dos princípios do respeito aos direitos humanos, à diversidade e à sustentabilidade socioambiental. Além disso, o PNE 2014 também estabelece metas e estratégias.

$\mathrm{Na}$ meta 14, há uma emenda, proposta e apresentada por 10 deputados/as, que adiciona uma nova estratégia e tem como redação:

desenvolver, garantir e ampliar a oferta de programas de formação inicial e continuada de profissionais do magistério [...] sobre sexualidade, diversidade, relações de gênero e Lei Maria da Penha no 11.340/03, em instituições de ensino superior públicas, visando superar preconceitos, discriminação, violência sexista e homofóbica no ambiente escolar (BRASIL, 2011).

A homofobia é uma das principais causas de discriminação nas escolas. De acordo com uma pesquisa realizada em 500 escolas, em 2010, pela Fundação Instituto de Pesquisas Econômicas (Fipe), 26,6\% dos/as alunos/as entrevistados/as concordaram com a afirmação "eu não aceito a homossexualidade"; $25,2 \%$ concordaram com "pessoas homossexuais não são confiáveis"; $23,2 \%$ com "a homossexualidade é uma doença"; $21,1 \%$ com "os alunos homossexuais não são normais" e $17,7 \%$ com "os alunos homossexuais deveriam estudar em salas separadas".

\section{ORIENTAÇÃO OU EDUCAÇÃO SEXUAL: A TEMÁTICA SEXUALIDADE E GÊNERO NA ESCOLA}

Há na literatura um debate a respeito de qual o termo mais adequado quando se fala sobre esse tema nas escolas: educação ou orientação sexual?

Inicia-se entendendo a sexualidade pelas proposições de Foucault (1990), que historiciza o quanto, nos três últimos séculos, existiu uma preocupação e disseminação exagerada em torno do sexo. Dessa forma, o que prevalece e aparece é o sexo como segredo e um problema a ser controlado. As palavras para expressá-lo são disciplinadas e controladas. Elege-se onde e quando, em quais situações e quem poderia falar sobre sexo. Para tanto, a escola passa a ser uma das instituições liberadas para falar do assunto, para controlar os corpos. Segundo Moura (2010), a partir do século XVIII, as escolas multiplicam-se, aperfeiçoam-se e aparecem como um dispositivo de poder.
Mesmo que na genealogia foucaultiana o autor tenha como estudo a análise e a constituição histórica das relações de poder em seu caráter produtivo e eficaz, ele questiona a concepção filosófica moderna do sujeito constituinte. E a substitui pela compreensão do sujeito como algo constituído historicamente de forma simultânea à constituição das práticas e dos discursos que se multiplicaram nas diversas instituições sociais nascentes, a partir do século XVII, tais como o quartel, a fábrica, a escola. Dessa forma, a função da escola era disciplinar o corpo e o sexo do homem e da mulher. A sexualidade das crianças era um dos alvos principais de preocupação, pois na criança estava o adulto do futuro. Os médicos e pedagogos passaram a vigiar os hábitos solitários das crianças com o propósito de evitar o seu maior e mais perigoso vício: o onanismo (masturbação), que era visto como uma das patologias mais sérias daquela sociedade, como se pode perceber na citação:

\begin{abstract}
Os pedagogos e os médicos combateram, realmente, o onanismo das crianças como uma epidemia a ser extinta. De fato, ao longo desta campanha secular, que mobilizou o mundo adulto em torno do sexo das crianças, tratou-se de apoiá-la nesses prazeres tênues, de constituí-los em segredos [...]; em todo canto onde houvesse o risco de se manifestarem, foram instalados dispositivos de vigilância, estabelecidas armadilhas para forçar confissões, impostos discursivos inesgotáveis e corretivos; foram alertados os pais e educadores, sendo entre eles semeada a suspeita de que todas as crianças eram culpadas e o medo de que eles próprios viriam a ser considerados culpados caso não desconfiassem suficientemente: tiveram de permanecer vigilantes diante desse perigo recorrente, foi prescrita a sua conduta e recodificada a pedagogia; e implantadas sobre o espaço familiar as bases de todo um regime médico-sexual (FOUCAULT, 1990, p. 71).
\end{abstract}

Ao longo da história, a sexualidade infantil não foi silenciada, ao contrário, ela foi assunto de diferentes especialistas da família e das instituições educacionais (FOUCAULT, 1997, p. 37).

Ainda em se tratando da sexualidade e da escola ao longo da história, pode-se remontar também ao aparato de dispositivos arquitetônicos, mobiliários, vestimentas de vigilância e controle das manifestações de ordem sexual de crianças e jovens nos internatos, colégios e demais instituições escolares. Todos estes visando à aplicação de toda uma ortopedia moral sobre o corpo e sobre a alma dos jovens, em uma etapa especialmente idônea para ser moldada, marcada, uma vez que se justifica a necessidade de seu governo específico, que dará lugar à emergência de dispositivos institucionais (VARELA; ALVAREZ-URIA, 1992, p. 6). 
Esses dispositivos institucionais são os espaços pensados e projetados intencionalmente para a educação de crianças e jovens com o objetivo de regular as atividades destes: "O espaço da sala, a forma das mesas, o arranjo dos pátios de recreio, a distribuição dos dormitórios [...], os regulamentos elaborados para a vigilância do recolhimento e do sono, tudo fala da maneira mais prolixa da sexualidade das crianças" (FOUCAULT, 1984, p. 30).

No Brasil, as primeiras preocupações explícitas em relação à educação do sexo de crianças e jovens foram inicialmente observadas nos anos 1920 e 1930. Porém, é importante salientar que médicos, professores e demais profissionais da saúde preocupavam-se com a educação sexual na educação brasileira, como os educadores brasileiros nas reformas educacionais no Brasil, a chamada proposta da Escola Nova, em meados dos anos 1920. Esta era fomentada pela medicina higienista da época, destacando-se a importância do ensino da matéria de educação sexual, cujo texto enfatizava para o interesse moral e higiênico do indivíduo e para o "interesse da raça" (MARQUES, 1994).

Ou seja, assim como ocorreu na história da sexualidade e da educação sexual nas escolas europeias, da mesma forma, no Brasil, a educação sexual foi influenciada pelas concepções médico-higienistas, preocupadas em combater a masturbação, as doenças venéreas e em preparar a mulher para o papel de esposa e de mãe. Em nosso país, uma das práticas mais perseguidas e condenadas por médicos e pedagogos foram as manifestações de masturbação, pois estas eram consideradas uma doença, um desvio moral. Foucault (1992) relata que os sintomas de magreza, de calafrios, de sistema nervoso abalado eram considerados oriundos dessa prática, de acordo com diagnósticos médicos.

A educação da criança deveria então estar voltada a evitar esse "mal" da masturbação, e todos os profissionais deveriam estar atentos para evitar tal conduta. No caso da escola militar, a luta contra o homossexualismo e contra a masturbação é contada pelas próprias paredes (FOUCAULT, 1992, p. 213).

É importante fazer uma distinção entre orientação e educação sexual. Existem algumas definições para esses termos; no entanto, não há uma padronização para as suas utilizações. Figueiró (1995) aponta a diversidade dos termos encontrados como educação sexual, orientação sexual, informação sexual, que são utilizados como sinônimos, diferenciados e indiferenciados, depois confundidos. Segundo o Guia de Orientação Sexual (SUPLICY et al., 2005), a educação sexual é aquela que inclui todo o processo informal pelo qual se aprende sobre sexualidade ao longo da vida, seja através da família, da religião, da comunidade, dos livros ou da mídia, ou seja, não necessita de uma sistematização, é um processo informal.

Para Valladares (2000), o termo orientação sexual diferencia-se de educação sexual, uma vez que esta última diz respeito à experiência pessoal, ao conjunto de valores assimilados pela pessoa, através da família, do ambiente social, dos meios de comunicação e de tantos outros canais de informação.

Vitiello (1995), ao enfocar a educação sexual como sendo um processo, afirma que este ocorre ao longo da vida e é voltado para a formação de atitudes ligadas à maneira de viver a sexualidade. Ressalta que esse processo passa pela informação e orientação, mas que é muito mais amplo, pois significa formar, dando ao educando condições para que cresça interiormente. Segundo Valladares (2000), quando se fala em orientação sexual, está se referindo ao processo formal e sistematizado que pode e deve ocorrer dentro de instituições. Constitui-se de uma proposta objetiva de intervenção por parte dos educadores. O Guia de Orientação Sexual traz a seguinte definição:

O termo Orientação Sexual, quando utilizado na área de educação, deriva do conceito pedagógico de Orientação Educacional, definindo-se como o processo de intervenção sistemático na área da sexualidade, realizado principalmente em escolas. Pressupõe o fornecimento de informações sobre sexualidade e a organização de um espaço de reflexão e questionamentos sobre posturas, tabus, crenças e valores a respeito de relacionamentos e comportamentos sexuais (SUPLICY, 1994, p. 8).

Pode-se resumir, então, que a educação sexual é um processo amplo e informal. Enquanto a orientação sexual é um processo de instrução e informação; portanto, um processo formal de educação (MAIA, 2001; RIBEIRO, 1990; SAYÃO, 1997; SUPLICY, 1994). Ribeiro (1990) mostra que, além da escola, qualquer instituição pode desenvolver projetos de orientação sexual. Orfanatos, creches, comunidades, associações de bairro e sindicatos são espaços a serem conquistados para desenvolver programas de orientação sexual.

A partir da década de 1920, iniciou-se, ainda que de forma tímida, alguma preocupação com a educação sexual no campo da educação escolar. Para que a sociedade caminhasse em direção à modernização, era necessário que o indivíduo conhecesse a fisiologia sexual nos moldes do discurso higienista. Começou, então, por volta de 1928, a realização de congressos defendendo programas de educação sexual nas escolas para crianças com mais de 11 anos, lançando, assim, a ideia de que o espaço escolar seria um local apropriado para se discutirem os conhecimentos na área da sexualidade. 
Conforme Guimarães (1995), o jornal Diário da Noite publicou, em 1930, uma notícia a respeito de pesquisa pública para verificar a opinião das pessoas no apoio à realização da educação sexual pelas escolas, como forma de atender às preocupações da comunidade escolar e médica. E obteve como resposta uma grande aceitação por parte da população. Mas, como esse sempre foi e continua sendo um assunto "perigoso" para a sociedade, eram naturais pontos de divergências quanto à metodologia e aos conteúdos programáticos a serem aplicados. Dessa forma, a pesquisa não pôde avançar. Passados 87 anos, percebe-se a resistência sobrevivendo à urgência de se tratar o tema nas escolas.

De acordo com Guimarães (1995), nos anos anteriores à década de 1960 a educação pública ainda se configurava timidamente, sendo que pouco se avançou, e havia uma severa repressão à educação sexual nesse período. Mesmo antes do final da década 1960, quando ocorreu no país um momento de hipertrofia do autoritarismo, o sistema de ensino nacional era bastante repressivo, tanto a veiculação de informação sobre sexualidade humana quanto a manifestação da sexualidade entre estudantes (ROSEMBERG, 2001).

O Brasil passava por renovações pedagógicas, advindas do intenso movimento da educação popular freiriana, do crescente aumento de escolas públicas e do avanço no número de alunos e alunas nas escolas. Porém, com o advento do golpe militar de 1964, grande parte dessas iniciativas foi abortada em função da ideologia moralista defendida pelos militares. Embora fossem criadas propostas de renovação pedagógica com discursos voltados à prática da educação sexual, essas eram negadas (CÉSAR, 2009).

Apesar de nesses tempos de repressão e ditadura militar terem ocorrido tentativas de implantação de uma educação sexual como parte da instrução escolar e também surgido vasta literatura na área da sexualidade mostrando essa preocupação, a atitude predominante dos anos 1940 aos anos 1960 era de negação, imposição de tabus, ocultamento, proibição e obsessão em relação ao sexo Negação porque fazia todo o possível para reduzir a sexualidade a algo secreto, pois não se podia falar sobre esse assunto, somente para se auto acusarem em confissão ou como argumento de gracejo malicioso. "A imposição de tabu ocorria porque qualquer tema referente à sexualidade, embora enormemente carregado de significado e interesse, adquiria o caráter de intocável e indiscutível. [...] Quando, apesar de tudo, emergia alguma manifestação sexual, perseguiam-na com grande rigor a lei, a moral ou os costumes [...]" (LOPEZ; FUERTES, 2004, p. 23).

A década de 1960, no Brasil, foi marcada por mudanças políticas muito fortes, principalmente com o advento do golpe de 1964, quando os militares passaram a comandar os rumos do país. Repressão era a palavra do momento, e esse período repressivo deixou marcas no processo de implantação oficial da educação sexual nas escolas, pois todos os projetos e investidas nesse sentido foram barrados e, em termos oficiais, nada foi feito.

Em 1971, ocorreu a reformulação da LDB 4024, que deu origem à Lei 5.692/71. Nessa determinação legal, surge a obrigatoriedade da Orientação Educacional desenvolvida pelo orientador educacional com formação superior em todas as escolas. Esse profissional, embora sem formação específica na área da sexualidade, acabou por enveredar por esse caminho devido ao caráter de proximidade e intimidade com o problema do educando no desenvolver do processo educativo. Ainda, de acordo com essa mesma lei, que fixa as diretrizes e bases para o ensino de $1^{\mathrm{O}}$ e $2^{\mathrm{o}}$ graus, não havia nenhuma proibição formal contra a educação sexual. Encontra-se sobre esse assunto o Parecer no 2.264/74, do Conselho Federal de Educação, aprovado em agosto de 1974, que menciona a educação sexual como um propósito a ser desenvolvido nos programas de Educação da Saúde em nível de 2 grau.

Fica evidente que somente os especialistas da educação e da saúde é que podem tratar do assunto. Essa preocupação decorre de um novo momento social-sexual surgido na década de 1960/1970. Nesse período, para contestar a repressão sexual, começaram a surgir por todo o país manifestações de repúdio ao modelo sexual repressor. Movimentos feministas e movimentos hippies, levantando a bandeira da liberdade, bem como o advento da pílula anticoncepcional, trouxeram à tona um novo modelo de comportamento sexual. Nos anos 1980, essa nova situação requereu da educação formal diretrizes para nortear esse novo modelo de comportamento sexual.

Os anos 1978 e 1979 foram marcados por uma intensa proliferação de congressos, debates e eventos sobre educação sexual. Estes se deram principalmente nas escolas de iniciativa privada. Percebeu-se que houve o interesse de diferentes segmentos da sociedade e profissionais ligados à saúde e à educação. Todavia, esses movimentos e iniciativas ratificavam a visão da sexualidade reduzida ao sexo, à contracepção e aos conceitos biológicos, objetivando em geral o controle preventivo de doenças e a gravidez precoce. No entanto, convém também salientar que o aparecimento da Aids e a propagação de outras doenças sexualmente transmissíveis entre os adolescentes e jovens instigaram as discussões nesse período (GUIMARÃES, 1995).

A respeito das discussões de Louro sobre esse período importante, no qual novas configurações no campo da sexualidade e gênero se fazem presentes, constata-se que: 
de fato, a partir da segunda metade dos anos 1980, no Brasil, passou-se a discutir muito mais a sexualidade (e a homossexualidade) em várias instâncias sociais, inclusive nas escolas. A preocupação em engajar-se no combate à doença (Aids) fez com que organismos oficiais, tais como o Ministério da Educação, passassem a estimular projetos de educação sexual, e, em 1996, o MEC incluiu a temática, como tema transversal, nos seus Parâmetros Curriculares Nacionais (os PCNs, a nova diretriz para a educação do País). Vale notar, contudo, que as condições que possibilitaram a ampliação da discussão sobre a sexualidade também tiveram o efeito de aproximá-la das ideias de risco e de ameaça, colocando em segundo plano a associação ao prazer e à vida (LOURO, 2008, p. 36).

As DSTs, a gravidez na adolescência e o aparecimento do HIV e da Aids exigiram uma preocupação maior das autoridades, e, a partir de meados dos anos 1980, a demanda por orientação sexual nas escolas se intensificou. $\mathrm{O}$ avanço da Aids e das DSTs trazem a necessidade de implantação de uma educação sexual escolar.

A escola, sendo um espaço de convivência social, amorosa, emocional do jovem e onde ele permanece boa parte de sua vida, não pode se omitir diante da gravidade da doença, considerando que a sua principal via de transmissão é a sexual, por isso a necessidade de um trabalho de educação sexual escolar com os alunos. Foi necessário que surgisse algo tão ruim como o HIV e a Aids para que a sexualidade do homem e da mulher fosse pensada pela educação, e não como parte integrante da vida de qualquer ser humano, mas sim como um dispositivo que tem como função principal responder a uma emergência, a da doença (BRASIL, 1995).

\section{CONCLUSÃo}

Analisando o início da explanação a respeito dos documentos legais a partir da Declaração Universal dos Direitos Humanos, destaca-se que esta foi adotada pelas Nações Unidas, em 1948, e representa um marco básico: "Todos os seres humanos nascem livres e iguais em dignidade e direitos, sem distinção de raça, cor, sexo, idioma, religião, origem nacional ou social, posição econômica e nascimento". Entretanto, é importante ressaltar que esses pressupostos básicos são um ponto de partida rumo à luta dos movimentos sociais feministas, à luta pelos direitos humanos em relação à sexualidade e à reprodução, e também pelo combate à homofobia e pela promoção da saúde da população de lésbicas, gays, bissexuais, travestis e transexuais. Entende-se que os movimentos feministas dão sentido a essa discussão que se iniciou na década de 1940 .

A Constituição da República Federativa do Brasil refere-se à ideia de "promover o bem de todos, sem preconceitos de origem, raça, sexo, cor, idade e quaisquer outras formas de discriminação" (Art. 3ํ, IV). No entanto, ressalta-se que a escola vai no mesmo sentido da sociedade. As considerações de Louro (2014) remetem à análise de ser indispensável que se reconheça que a escola não apenas reproduz ou reflete as concepções de gênero e sexualidade que circulam na sociedade, mas que ela própria se produz.

O ECA (1990) destaca a sexualidade como a dimensão humana mais ampla. Dessa forma, a verdade ou o saber sobre as pessoas ou grupos sociais em relação a essa questão tornam-se questionáveis devido à extensão da temática. Já com a aprovação da LDB 9.394/96 e com a implantação dos Parâmetros Curriculares Nacionais (1998), em seu contexto mais geral, por áreas do conhecimento, foi proposta a reestruturação das disciplinas dos ensinos fundamental e médio e a inclusão dos temas transversais, entre eles a sexualidade, como indispensáveis para a formação escolar e social. Entende-se que o conceito de transversalidade ainda deve ser mais explorado, como "[...] um princípio teórico do qual decorrem várias consequências práticas, tanto nas metodologias de ensino quanto na proposta curricular e pedagógica" (SANTOS, 2010, p. 74). Isto é, a sua implementação deve acontecer nas discussões iniciais para a construção de currículos, de metodologias e práticas pedagógicas efetivas em sala de aula.

Quanto ao Plano Nacional de Educação 2011-2020, recente pesquisa da Undime ${ }^{2}$ constata que há um conjunto de 18 emendas, estratégias e metas para o Projeto de Lei do PNE atual referente a questões que envolvam gênero e sexualidade.

Resta aguardar e seguir entendendo que as leis e políticas relativas a sexualidade e gênero devem ir em direção a uma efetiva prática de propostas sociais e educacionais para a superação e visão superficial de que o corpo e sua concepção anatômica inscrevem a homens e mulheres a naturalização sexual. Em outras palavras, aquilo que é nato, natural, dado e inato, características que os diferenciam. Nessa linha de pensamento, as diferenças e desigualdades constituídas sobre homens e mulheres não são da ordem da biologia, e sim sociais, culturais e historicamente construídas e situadas, não determinadas somente pelo viés biológico, da anatomia de seus corpos. Diferentes sexualidades podem ser constituídas, porém percebe-se que as escolas ainda trabalham na educação sexual somente com o sentido biológico, naturalizado e reprodutor.

Para Louro (2007), as questões de gênero vão em direção ao caráter efêmero e transitório do corpo. A ideia de base biológica e binária (homem x mulher) vai dando

\footnotetext{
${ }^{2}$ Undime - União Nacional do Dirigentes Municipais de Educação.
} 
abertura e espaço nas teorizações para o entendimento de que o corpo (e a sexualidade) é constructo social, cultural, político e historicamente engajado, constituído e situado, marcado por signos e códigos do tempo presente.

Para finalizar, concorda-se com a necessidade de analisar preconceitos existentes realizando uma leitura do espaço escolar com o objetivo de desconstruí-los (MADUREIRA e BRANCO, 2012). Questiona-se como efetivamente se pode pensar na desconstrução dos preconceitos no espaço escolar para implementar um espaço inclusivo, onde todos possam participar e (con) viver, atendendo aos textos legais referidos ao longo deste estudo? Propõe-se que se possa desfazer de atitudes reducionistas, reconhecer e respeitar as diferenças, em tempos onde o conservadorismo extremo reaparece, excluindo dos espaços escolares e sociais o estranho, o diferente. Isso porque ele é, em alguma medida, a "face oculta da minha identidade" (KRISTEVA, 1994). Entende-se, como escreveu Arend (apud SCHIO, 2006, p. 70), que "nós resistimos ao mal em não sendo levados pela superfície das coisas, em parando e começando a pensar, ou seja, em alcançando uma outra dimensão que não o horizonte de cada dia. Em outras palavras, quanto mais superficial alguém for, mais provável será que ele ceda ao mal".

\section{REFERÊNCIAS}

BRASIL. Decreto-Lei 869/1969. Disponível em: $<\mathrm{http}: / / w w w$. planalto.gov.br/ccivil 03/LEIS/1989_1994/L8663.htm\#art1>. Acesso em: 27 nov. 2017.

BRASIL. Constituição da República Federativa do Brasil de 1988. Disponível em: <http://www.planalto.gov.br/ccivil 03/ constituicao/constituicaocompilado.htm> Acesso em: 27 nov. 2017.

BRASIL. Lei no 8.069, de 13 de julho de 1990. Dispõe sobre o Estatuto da Criança e do Adolescente e dá outras providências. Disponível em: <http://www.planalto.gov.br/ccivil_03/leis/ L8069.htm>. Acesso em: 27 nov. 2017.

BRASIL. Declaração de Salamanca, 1994. Disponível em: $<$ http://portal.mec.gov.br/seesp/arquivos/pdf/salamanca.pdf $>$. Acesso em: 27 nov. 2017.

BRASIL. Lei no 9.394. Lei de Diretrizes e Bases da Educação (LDB), de 26 de dezembro de 1996. Disponível em: <http:// www.planalto.gov.br/ccivil 03/leis/L9394.htm>. Acesso em: 27 nov. 2017.

BRASIL. Secretaria de Educação Fundamental. Parâmetros curriculares nacionais: apresentação dos temas transversais, ética. Brasília: MEC/SEF, 1997.

BRASIL. Secretaria de Educação Fundamental. Parâmetros curriculares nacionais: terceiro e quarto ciclos: apresentação dos temas transversais. Brasília: MEC/SEF, 1998.

BRASIL. PCNS - Temas transversais, 1998. Disponível em: $<$ http://portal.mec.gov.br/seb/arquivos/pdf/ttransversais.pdf>. Acesso em: 27 nov. 2017.
BRASIL. Brasil sem homofobia. 2004. Disponível em: $<$ http:/ bvsms.saude.gov.br/bvs/publicacoes/brasil_sem_homofobia. pdf> Acesso em: 27 nov. 2017.

BRASIL. Plano Nacional de Políticas para Mulheres. 2004. Disponível em <http://www.spm.gov.br/assuntos/pnpm/planonacional-politicas-mulheres.pdf>. Acesso em: 27 nov. 2017.

BRASIL. 3a Conferência Nacional para Mulheres 2011. Disponível em: <http://www.spm.gov.br/assuntos/pnpm/ publicacoes/anais-da-3a-conferencia>. Acesso em: 27 nov. 2017.

BRASIL. Lei no 13.005, de 25 de junho de 2014. Aprova o Plano Nacional de Educação - PNE e dá outras providências. Disponível em: <http://www.planalto.gov.br/ccivil_03/ Ato2011-2014/2014/Lei/L13005.htm>. Acesso em: 20 jul. 2015.

CÉSAR, M. R. de A. Lugar de sexo é na escola? Sexo, sexualidade e educação sexual. In: Sexualidade. Secretaria de Estado da Educação. Superintendência de Educação. Departamento de Diversidades. Núcleo de Gênero e Diversidade Sexual. Curitiba: Seed - PR, 2009. p. 49-58.

CRUZ, Lilian Moreira. Discursos cambiantes sobre corpo, gênero e sexualidade no curso de Pedagogia da Uesb. Jequié: Uesb, 2014

DECLARAÇÃO MUNDIAL DE EDUCAÇÃO PARA TODOS. 1990. Disponível em: <http://unesdoc.unesco.org/ images/0008/000862/086291por.pdf>. Acesso em: 27 nov. 2017.

DECLARAÇÃO UNIVERSAL DOS DIREITOS HUMANOS. 1948. Disponível em: <http://unesdoc.unesco.org/images/ 0013/001394/139423por.pdf>. Acesso em: 27 nov. 2017.

DALLARI, de Abreu. O futuro do Estado. São Paulo: Saraiva, 2007.

FIGUEIRÓ, M. N. D. Educação sexual: retomando uma proposta, um desafio. Londrina: UEL, 1995.

FOUCAULT. M. A história da sexualidade. 1: a vontade de saber. Rio de Janeiro: Graal, 1984.

FOUCAULT. M. A história da sexualidade. 1: a vontade de saber. Rio de Janeiro: Graal, 1990.

FOUCAULT. M. A história da sexualidade. 1: a vontade de saber. Rio de Janeiro: Graal, 1997.

FOUCAULT. M. Microfísica do poder. Rio de Janeiro: Graal, 1992.

GORE, J. M. Foucault e a educação: fascinantes desafios. In: SILVA. Tomaz Tadeu da. O sujeito da educação: estudos foucaultianos, 2. ed. Petrópolis, RJ: Vozes, 1995.

GUIMARÃES, I. Educação sexual na escola: mito e realidade. Campinas, SP: Mercado de Letras, 1995.

KRISTEVA, Julia. Estrangeiros para nós mesmos. Rio de Janeiro: Rocco, 1994.

LIMONGI, Rubens (Coord.). Enciclopédia Saraiva do Direito. São Paulo: Saraiva, 1977. v. 22.

LIRA, A.; JOFILI, Z. O tema transversal orientação sexual nos PCN e a atitude dos professores: convergentes ou divergentes? Ensino, Saúde e Ambiente, Niterói, v. 3, n. 1, p. 22-41, 2010. Disponível em: $<\mathrm{http}: / / \mathrm{www} . e n s i n o s a u d e a m b i e n t e . u f f . b r / i n d e x$. 
php/ensino saudeambiente/article/view/105/104>. Acesso em: 27 nov. 2015.

LOPEZ, F.; FUERTES, A. Para comprender la sexualidad. Navarra: Verbo Divino, 2004.

LOURO, Guacira Lopes. Gênero, sexualidade e educação: uma perspectiva pós-estruturalista. Petrópolis: Vozes, 2004.

LOURO, Guacira Lopes. Gênero e sexualidade: pedagogias contemporâneas. Pro-Posições, v. 19, n. 2 (56), maio/ago. 2008. Disponível em: <http://www.scielo.br/pdf/pp/v19n2/a03v19n2. pdf>. Acesso em: 1 dez. 2014.

MAIA. A. C. B. Reflexões sobre a educação sexual da pessoa com deficiência. Revista Brasileira de Educação Especial, Marília, v. 7, n. 1, 2001.

MARQUES, V. B. A medicalização da raça. Médicos, educadores e discurso eugênico. Campinas: Ed. Unicamp, 1994.

MOURA, T. M. de. Foucault e a escola: disciplinar, examinar, fabricar. Dissertação (Mestrado) - Universidade Federal de Goiás, Faculdade de Educação, 2010.

PIROTTA, W. R. B.; PIROTTA, K. C. M. O adolescente e o direito à saúde após a Constituição de 1988. In: SCHOR, N.; MOTA, M. S. F. T.; BRANCO, V. C. (Org.). Cadernos Juventude, Saúde e Desenvolvimento. Brasília, DF: Ministério da Saúde: Secretaria de Políticas de Saúde, 1999.

QUARESMA DA SILVA, Denise R. Educação (des) encantada: pedagogias de gênero nas práticas de educação sexual de instituições escolares do Brasil, 2012.

QUARESMA DA SILVA, Denise R. Tratamiento de la educación sexual en escuelas primarias en el sur de Brasil, 2014.

RIBEIRO, P. R. M. Educação sexual além da informação. São Paulo: EPU, 1990.

RIBEIRO, P. R. M. (Org). Sexualidade e educação: aproximações necessárias. São Paulo: Arte \& Ciência, 2004.

ROSEMBERG. F. Políticas educacionais e gênero: um balanço dos anos 1990. Cadernos Pagu, Rio de Janeiro, v. 16, p. 151-197, 2001.
SANTOS, M. A. Orientação sexual no 10 e 20 ciclos do ensino fundamental: uma realidade distante? 2001. Monografia (Pedagogia) - Universidade Federal do Rio Grande do Norte, 2001.

SAYÃO, Y. Orientação sexual na escola: os territórios possíveis e necessários. In: AQUINO, J. G. (Org.). Sexualidade na escola: alternativas teóricas e práticas. São Paulo: Summus, 1997. p. 107-117.

SCHIO. Sônia Maria. Hannah Arendt: história e liberdade (da ação à reflexão). Caxias do Sul: Educs, 2006.

SUPLICY, M. et al. Educação e orientação sexual. In: RIBEIRO. Novas ideias: novas conquistas. Rio de Janeiro: Rosa dos Tempos, 1994.

SUPLICY, M. et al. O trabalho de orientação sexual: objetivos e valores. In: SUPLICY, M. Guia de orientação sexual: diretrizes e metodologia. Tradução Joyce Kacelnik, 6. ed. São Paulo: Casa do Psicólogo, 2005.

TRAVERSINI, C. S.; COSTA, Z. L. S. Formas de ensinar produzem o aprender? VI Seminário de Pesquisa em Educação da Região Sul. Anais. Santa Maria, RS: UFSM, 2006.

VALLADARES, K. K. Orientação sexual na escola. Rio de Janeiro: Quartet, 2000.

VARELA, Julia; ALVAREZ-URIA, Fernando. A maquinaria escolar. In: Teoria e Educação, Porto Alegre, v. 6, p. 68-96, 1992.

VITIELlO, N. A. Educação sexual necessária. Revista Brasileira de Sexualidade Humana, São Paulo, v. 6, n. 1, p. 15-28, 1995.

WEEKS, J. O corpo e a sexualidade. In: LOURO, Guacira Lopes (Org.). O corpo educado: pedagogias da sexualidade. Belo Horizonte: Autêntica, 1999.

Recebido em 25-01-2018

Aprovado em 12-03-2018. 